\title{
In Vitro Modelling of Barrier Impairment Associated with Gastro-Oesophageal Reflux Disease (GERD)
}

\section{Marisa Meloni (iD \\ Paolo Buratti \\ Francesco Carriero Laura Ceriotti (D)}

VitroScreen, In Vitro Innovation Center, Milan, 20I49, Italy
Correspondence: Laura Ceriotti Via Mosè Bianchi, I03, Milan, 20149, Italy Tel +390289077608

Email laura.ceriotti@vitroscreen.com
Purpose: A novel experimental model based on a 3D reconstructed human oesophageal epithelium model $(\mathrm{HO} 2 \mathrm{E})$ has been developed to investigate the structural and functional changes of the oesophageal epithelium following exposure to a solution of $\mathrm{HCl} 0.1 \mathrm{~N}(\mathrm{pH}=$ 1.2) mirroring GERD microenvironment condition.

Methods: The barrier structure modification after the exposure to the acid solution on $\mathrm{HO} 2 \mathrm{E}$ tissues was investigated immediately after damage induction and after 1 hour post incubation and compared to HO2E tissues exposed to phosphate buffered saline solution. Immunofluorescence (IF) was applied to quantify the expression and localization of barrier function proteins: Claudin-1 (CLDN-1), Claudin-4 (CLDN-4), Zonulin-1 (ZO-1), E-Cadherin and Mucin-1 (MUC1). Barrier functionality was measured by TEER.

Results: In the acidic microenvironment, TEER measurement has shown some limitations and results were not applicable, whereas the evaluation of protein localization and quantification provided clear and robust evidence of the damage which occurred to the epithelium barrier structure. CLDN-4 expression significantly decreased after exposure to acid. ZO-1 protein appeared upregulated immediately after exposure to $\mathrm{HCl}$ and was mainly localized in the cytoplasm and not on the cell membrane. This different localization was also observed for CLND-1. CLDN-1, MUC1 and, to a lower extent, ZO-1 expression increased during the post-incubation period.

Conclusion: The relevant tissue biomarkers identified, CLDN-1 and MUC1, can be used to monitor TJ structure and epithelial barrier recovery after acid-induced damage which, in our experimental conditions, were non-destructive and suitable for recovery studies. The established model can be useful to investigate the mechanism of action of formulations acting on this specific pathophysiological condition and/or designed to potentiate the physiological defense mechanisms of oesophageal mucosa.

Keywords: gastro-oesophageal reflux disease, GERD, 3D reconstructed human oesophageal epithelium, Claudin-1, Claudin-4, E-Cadherin, Zonulin-1, Mucin-1, TEER measurement

\section{Introduction}

Gastro-oesophageal reflux disease (GERD) is a chronic disorder caused by prolonged exposure of the distal oesophagus to acid gastric contents. ${ }^{1}$ Approximately $10-20 \%$ of people in the Western world have GERD, with at least weekly heartburn and/or acid regurgitation. ${ }^{2}$ GERD significantly impacts patient's quality of life and may lead to long-term complications, such as Barrett's oesophagus (BE) and can be a cause of oesophageal adenocarcinoma (ADC). 
The first structure protecting the oesophageal epithelium from gastric fluids is represented by the mucus layer covering the oesophageal mucosa. ${ }^{3}$ Mucin glycoproteins (MUC2 and MUC1) expression has been shown to considerably increase in response to acid and pepsin; ${ }^{4}$ furthermore a different expression of mucins (MUC1, MUC2, MUC5AC and MUC6) is found in patients with $\mathrm{BE}$ and $\mathrm{ADC}$. $^{5,6}$

The second intrinsic defense mechanism of the oesophageal epithelium is the epithelial barrier structure. The integrity of the oesophageal epithelium is dependent on the mechanical cohesion between epithelial cells thanks to the apical junction complexes: adherents' junctions, desmosomes and tight junctions (TJs). The TJs in particular make the epithelium act as a barrier to the passage of ions and solutes and are composed of functional proteins, which interact to form the architecture of epithelial barriers: ${ }^{7}$ Claudin, Occludin and JAMs are transmembrane proteins that connect cells to the adjacent ones and Zonulin acts as a link for the TJ with the cytoskeleton of the cell. E-cadherin, a component of the adherents' junction, is also known to contribute to integrity of the barrier in most epithelia, including the oesophagus. ${ }^{8}$

Prolonged exposure to gastric fluids results in an impairment of both the intrinsic defense mechanisms of the oesophageal epithelium. The following mechanisms are described in the literature findings based on ex-vivo and in vitro studies: deregulation and mis-localization of proteins of apical junction complexes, ${ }^{9}$ impairment of mucin secretion, ${ }^{4,10}$ decrease of Trans Epithelial Electrical Resistance (TEER) values, ${ }^{11,12}$ and disruption of cell-cell junctions. ${ }^{13-16}$ The modifications described in the literature on human explants or air-liquid interface systems resulted in dilated intercellular spaces (DIS) between oesophageal epithelial cells, characteristic of oesophageal biopsies from GERD patients. ${ }^{17,18}$

Biological models currently available to evaluate mechanisms of treatments at tight junction and mucin level include endoscopic biopsies from patients with GERD related symptoms, ${ }^{9,15}$ in vivo surgical models in rat or mice, ${ }^{14,19} \mathrm{ex}-$ vivo swine model, ${ }^{20}$ in vitro oesophageal epithelial cell line monolayers, ${ }^{21}$ and in vitro culture model of stratified squamous epithelium based on primary human oesophageal epithelial cells (HEECs). ${ }^{13,22}$ Based on the use of these models, the detrimental action of acidic reflux and duodenal reflux components as well as the mechanisms of action of therapeutic agents have been better understood. However, these models have some limitations. In particular, they lack reproducibility and versatility, and they have ethical concerns (human biopsies and animal model).
Since gastric acid plays a key role in the pathogenesis of GERD, luminal pH control is considered important in the management of this disease. Antisecretory drugs, such as histamine $\mathrm{H} 2$ receptor antagonists and proton pump inhibitors, have been shown to be effective against GERD. ${ }^{23}$ However, the response to these medications is variable, suggesting that an efficient treatment should have the epithelial barrier as principal target. More recently, new formulations as alternatives to antacids have been developed taking into account the molecular mechanisms responsible for GERD-induced damage to the oesophageal epithelium. ${ }^{4,14}$

The necessity of alternative and more performant medications has led to an increase in R\&D activities determining both a deeper understanding of the mechanisms inducing epithelium damage and the development of appropriate preclinical models and protocols suitable for formulation screening and product efficacy evaluation.

In this study, a novel pre-clinical experimental model based on a new, reproducible and commercially available $3 \mathrm{D}$ human reconstructed human oesophageal epithelium tissue (HO2E) has been developed to investigate the structural and functional changes of the oesophageal epithelium following exposure to acid intestinal fluid $(\mathrm{HCl} 0.1 \mathrm{~N}, \mathrm{pH} 1.2)$ mirroring refluxates on GERD microenvironment conditions. We have considered fundamental to adopt a histomorphological approach to characterize the 3D human tissues in order to use it to recapitulate barrier damage with modifications of barrier protein expressions and localization. Literature reports deregulation and mis-localization of proteins of the apical junction in the case of GERD as relevant and representative parameters of a symptoms persistency. ${ }^{9,24}$ The effects of the acidic solution at $\mathrm{pH} 1.2$ after 1 hour exposure on $\mathrm{HO} 2 \mathrm{E}$ epithelium were investigated immediately after the induction of acute damage and after 1 hour post incubation period. For both conditions, immunofluorescence (IF) was used to quantify the expression of specific TJs proteins and the applicability of a functional measure of the barrier integrity and fence properties (TEER measure) has been investigated.

\section{Materials and Methods Reagents}

$\mathrm{HCl}$ was purchased from Supelco (Bellefonte, PA, USA), Phosphate Buffer Saline (PBS) from Sigma Aldrich (St. Louis, MO, USA) and Saline Solution from Eurospital (Trieste, Italy). 


\section{Test System}

The SkinEthic $^{\mathrm{TM}}$ Oesophageal Epithelium (HO2E) was provided by EPISKIN (Lyon, France). The epithelium is formed after 5 days of airlift culture of the Kyse 510 cell line (derived from human oesophageal squamous cell carcinoma) on inert polycarbonate filters in a chemically defined medium to reproduce the human oesophageal epithelium morphology. The epithelium is $0.5 \mathrm{~cm}^{2}$ large with an average thickness between 65-80 $\mu \mathrm{m}$.

The batch was tested for the absence of hepatitis B, hepatitis $\mathrm{C}$ and mycoplasma, and the maintenance medium was tested for sterility. The inserts containing the tissues at day 5 were placed at room temperature in a multi-well plate filled with an agarose nutrient solution in which they were embedded for shipment.

After arrival, the HO2E were removed from the agarose nutrient solution under a sterile airflow cabin. The inserts were rapidly transferred to 6-well plates previously filled with specific growth medium $(1 \mathrm{~mL} /$ well) (EPISKIN, Lyon, France) at room temperature and incubated at $37^{\circ} \mathrm{C}, 5 \% \mathrm{CO}_{2}$ and saturated humidity. The growth medium was used for 7 days after tissue reception. The test was performed at 12 days of differentiation $(\mathrm{HO} 2 \mathrm{E} / 12)$ with tissues kept in maintenance medium till the end of the experiment. The study has been performed on triplicate tissues.

\section{Protocol}

At day 12, one hundred microliters of $\mathrm{HCl} 0.1 \mathrm{~N}$ solution (pH 1.2) were applied directly on the apical surface of $\mathrm{HO} 2 \mathrm{E}$ tissues for 1 hour \pm 10 minutes while tissues were kept at $37{ }^{\circ} \mathrm{C}, 5 \% \mathrm{CO}_{2}$ and saturated humidity.

At the end of the damage induction, the excess of the $\mathrm{HCl}$ solution was removed by a gentle rinse with $100 \mu \mathrm{L}$ of PBS. The tissues were used for analysis immediately after exposure (series $\mathrm{HCl} 0.1 \mathrm{~N}$ ) or were left for 1 hour at $37^{\circ} \mathrm{C}$, $5 \% \mathrm{CO}_{2}$ and saturated humidity with $100 \mu \mathrm{L}$ of fresh PBS on the tissues' surface (series $\mathrm{HCl} 0.1 \mathrm{~N}+1 \mathrm{~h}$ post incubation). The two series were compared to $\mathrm{HO} 2 \mathrm{E}$ tissues treated with PBS and used as negative control (NC). The HO2E tissues were then fixed in buffered formalin solution $10 \%$ and embedded in paraffin blocks; $5 \mu \mathrm{m}$ sections were cut and placed onto X-tra adhesive slides (Leica Biosystems).

\section{Trans Epithelial Electrical Resistance (TEER) Measurement}

TEER is an indirect assessment of tight junctions' stability and, consequently, a direct measure of the functionality of barrier function in epithelial tissues. It reflects the global resistance of the barrier linked both to the tissue's structure and to its thickness.

TEER was measured using the Millicell ${ }^{\circledR}$-ERS (Electrical Resistance System) instrument (Millipore Corporation, Bedford, MA, USA). The measure was performed 1 hour after acid treatment on tissues placed in 6-well plates previously filled with $5 \mathrm{~mL} /$ well of saline solution and $0.5 \mathrm{~mL}$ of saline solution were directly applied on the tissue's surface. The Millicell-ERS instrument was placed with the electrodes in the two chambers and the TEER was measured (range 0-20 $k \Omega$ ). Three measurements for each tissue were done and the mean TEER value of each tissue was calculated. The mean TEER value was then corrected considering the tissue surface $\left(0.5 \mathrm{~cm}^{2}\right)$ according to the following formula:

$\Omega / \mathrm{cm}^{2}=$ tissue $^{\prime}$ s mean TEER $(\Omega)$ xtissue surface $\left(0.5 \mathrm{~cm}^{2}\right)$

The mean TEER values of each series were then calculated. The results were expressed as \% with respect to negative control.

\section{Hematoxylin and Eosin (H\&E) Staining}

Hematoxylin and eosin (H\&E) staining is based on acidic/ basic properties of the chemicals: the hematoxylin stains cells blue whereas the eosin stains the extracellular matrix and cytoplasm pink. H\&E staining was performed on both HO2E tissues series and on a human oesophagus biopsy obtained from AMSBIO (Abingdon, UK). Specifically, the biopsy derived from a healthy Caucasian female, 40 years old (specimen ID: CU2008/20 2C-19 A).

The slides were deparaffinized, rehydrated, stained with H\&E, dehydrated and finally mounted with organolimonene and cover slips.

The tissues were evaluated by light microscopy using microscope LEICA DMi8 THUNDER imager 3D composed by camera DFC450 C. The entire $(100 \%)$ sections were acquired by LASX Tilescan (20x objective).

\section{Immunofluorescence Analysis (IF)}

Five proteins were investigated: Claudin-1 (CLDN-1), Claudin-4 (CLDN-4), Zonulin-1 (ZO-1), E-Cadherin and Mucin-1 (MUC1). The roles of these proteins and their expression/localization in GERD conditions are described in Table 1.

The slides were deparaffinized, rehydrated, treated with citrate buffer ( $\mathrm{pH}$ 6.0) as antigen retrieval, and blocked with bovine serum albumin in phosphate-buffered saline 
Table I Biological Role of Esophageal Barrier Biomarkers and Their Expression/Localization in GERD Conditions According to Literature Findings

\begin{tabular}{|c|c|c|}
\hline Protein & Biological Role & $\begin{array}{l}\text { Protein Expression Modification/ Localization in GERD } \\
\text { Condition }\end{array}$ \\
\hline $\begin{array}{l}\text { Claudin-I } \\
\text { Claudin-4 }\end{array}$ & $\begin{array}{l}\text { Transmembrane proteins contributing to the barrier function of } \\
\text { the stratified esophageal epithelium, predominantly localized on } \\
\text { the cell membrane of basal, supra-basal and superficial epithelial } \\
\text { layers. }\end{array}$ & $\begin{array}{l}\text { Claudin-I is reported to increase in erosive reflux disease (ERD) } \\
\text { and non-erosive reflux disease (NERD) in patient esophageal } \\
\text { biopsies. }{ }^{15} \\
\text { Claudin- } 4 \text { and Claudin-I expression is reported to decrease in } \\
\text { GERD patient biopsies. Furthermore, Claudin-I increases after } \\
\text { esophageal mucosa exposure to } 1.5 \mathrm{mM} \mathrm{DCA} \text { and } 0.04 \mathrm{mM} \\
\text { trypsin treatment in the Ussing chamber. By using } 2.5 \mathrm{mM} \mathrm{DCA} \\
\text { and trypsin, Claudin-4 significatively decreases while Claudin-I } \\
\text { remains unchanged. }\end{array}$ \\
\hline E-cadherin & $\begin{array}{l}\text { Transmembrane calcium-dependent cell adhesion protein } \\
\text { involved in mechanisms regulating cell-cell adhesions, mobility } \\
\text { and proliferation of epithelial cells. It is a ligand for integrin } \alpha E \beta 7 \text {. }\end{array}$ & $\begin{array}{l}\text { E-cadherins expression remains unchanged in GERD patients } \\
\text { compared with healthy subjects. However, it significatively } \\
\text { decreases after esophageal mucosa exposure to } 2.5 \mathrm{mM} \mathrm{DCA} \\
\text { and } 0.04 \mathrm{mM} \text { trypsin. }\end{array}$ \\
\hline Zonulin I & $\begin{array}{l}\text { Intracellular located adaptor protein that links TJ transmembrane } \\
\text { proteins such as claudins, junctional adhesion molecules and } \\
\text { occludin to the actin cytoskeleton. }\end{array}$ & $\begin{array}{l}\text { No change in Zonulin I expression is reported in GERD } \\
\text { patients. }{ }^{25}\end{array}$ \\
\hline Mucin I & $\begin{array}{l}\text { A transmembrane glycoprotein with extensive O-linked } \\
\text { glycosylation of its extracellular domain. Mucin I is present on } \\
\text { the apical surface of epithelial cells of the lung, stomach, } \\
\text { intestines, eyes, and a variety of hematopoietic cells. The main } \\
\text { function of Mucin I is to protect cells from infection by binding } \\
\text { to the pathogens with oligosaccharides in the extracellular } \\
\text { domain, thus preventing pathogens from invading cells. }\end{array}$ & $\begin{array}{l}\text { Mucins increase significantly in response to acid treatment in } \\
\text { order to counteract the surface corrosive effect. }{ }^{26}\end{array}$ \\
\hline
\end{tabular}

(to prevent non-specific binding) prior to treatment with specific antibodies.

\section{Claudin-I and Claudin-4 Double Immunostaining}

The slides were immunolabeled with primary antibodies such as rabbit polyclonal (pAb) anti-CLAUDIN-1 antibody (51-9000) (Invitrogen, USA), mouse monoclonal anti-CLAUDIN-4 antibody (32-9400) (Invitrogen, USA) and then incubated overnight at $+4{ }^{\circ} \mathrm{C}$.

The day after primary antibodies incubation, the slides were washed with PBS and incubated with Alexa Fluor 488 goat anti-mouse PLUS (A32723) (Invitrogen, USA) and Alexa Fluor 555 donkey anti-rabbit (A31572) (Invitrogen, USA) secondary antibodies. Finally, the sections were counter-stained with 4',6-diamidino-2-phenylindole (DAPI).

\section{ZO-I, E-Cadherin and MUCI Immunostaining}

The slides were immunolabeled using the following primary antibodies: a rabbit anti-ZO-1 polyclonal antibody (pAb) (33-9100) (Abcam, USA), a rabbit anti-E-CADHERIN polyclonal antibody (pAb) (HPA004812) (Sigma Aldrich, Germany), a rabbit anti-MUCIN 1 polyclonal antibody (pAb) (HPA004179) (Sigma Aldrich, Germany) and then incubated overnight at $+4{ }^{\circ} \mathrm{C}$.

The day after primary antibodies incubation, the slides were washed with PBS and incubated with goat anti-rabbit biotinylated secondary antibody (31822) (Invitrogen, USA) for the rabbit primary antibodies, followed by further incubation with streptavidin conjugate with Texas red (S872) (Invitrogen, USA).

The sections were counter-stained with 4',6-diamidino2-phenylindole (DAPI). 


\section{Fluorescent Signal Quantification}

The histological samples were analyzed in triplicate $(\mathrm{n}=$ 3) using the LED microscope LEICA DMi8 THUNDER imager 3D composed by camera $\mathrm{K} 5$.

For each biological replicate, the entire sections were acquired by LASX Tilescan technology and quantified using LASX 3.7.1 software. Representative images at $63 \mathrm{X}$ magnification were acquired. Signal quantification was performed considering the Sum intensity of area covered by fluorescence signal; the mean and standard deviation of biological replicates were calculated.

\section{Statistical Analysis}

Statistical analysis was performed using one-way ANOVA with post-hoc Tukey HSD Test and statistically significant results were reported as $\mathrm{p}$-value $(\mathrm{p}<0.05$ and $\mathrm{p}<0.01)$.

\section{Results and Discussion Oesophageal Epithelium Morphology: H\&E Staining}

The structure of the oesophageal epithelium is characterized by a basal layer consisting of a regular column cuboidal cells shape, an intermediate layer (spinous layer) with polygonal cells that allows an increase in the epithelium tensile strength and a non-keratinized superficial layer (squamous), organized in a continuous layer in which the cell-cell interaction is significantly reduced (Figure 1A).

The 3D reconstructed oesophageal epithelium after 5 days of differentiation (Figure 1B) presents a similar architecture to the ex vivo epithelium. However, the most superficial layer, squamous, shows a more homogeneous epithelium continuity (because of stronger cell-cell adhesion due to the airlift culture) and compactness compared to ex vivo structure.

A
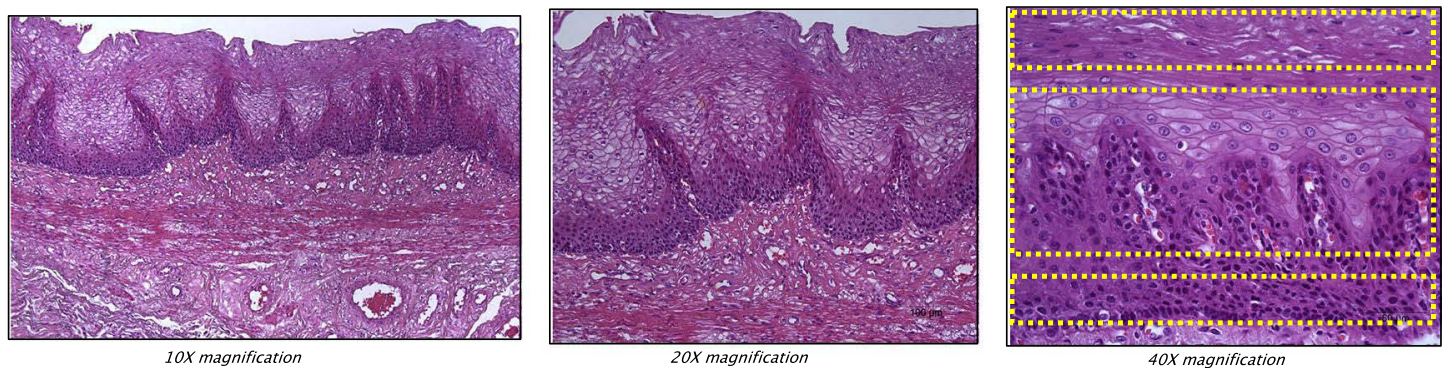

Superficial layer

$20 X$ magnification

$40 X$ magnification

Superficial layer

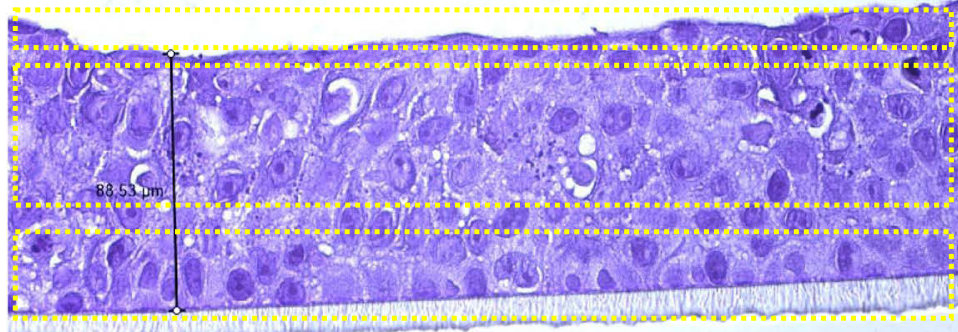

intermediate layer (Spinous layer)

B

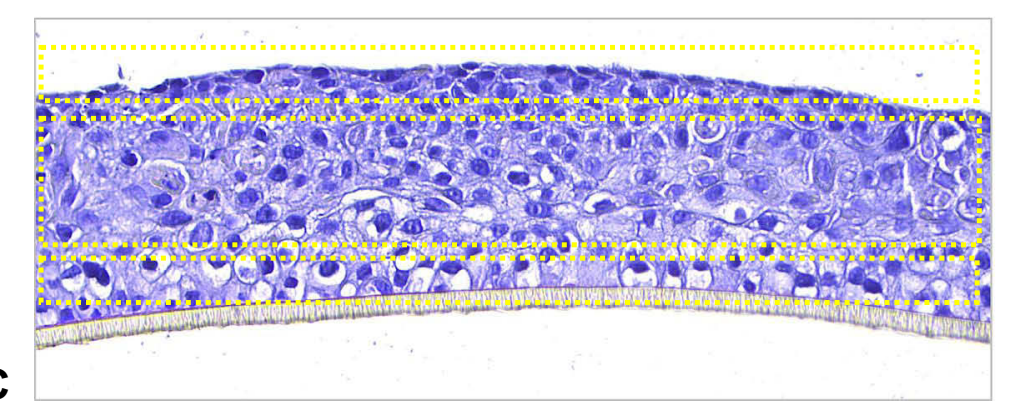

Superficial layer

intermediate layer

(Spinous layer)

Basal layer

Figure I H\&E staining of healthy human female oesophageal biopsy (A), human reconstructed oesophageal epithelium after 5 days of differentiation (B) and after 12 days of differentiation $(\mathbf{C})$. The yellow dashed rectangles underline the location of the different cell layers present both in the human explant and in the 3D reconstructed tissue. 


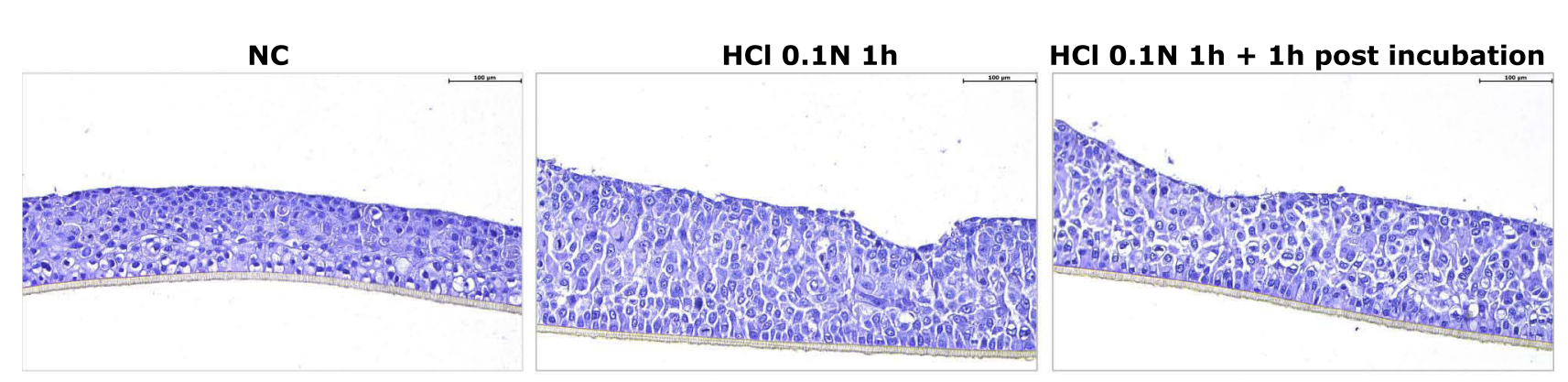

Figure $2 \mathrm{H} \& \mathrm{E}$ staining performed on $\mathrm{HO} 2 \mathrm{E} / \mathrm{I} 2$ treated with buffered saline solution (NC), with $\mathrm{HCl} 0 . \mathrm{IN}$ during $\mathrm{Ih}$ (series $\mathrm{HCl} 0 . \mathrm{IN} \mathrm{Ih}$ ) or with $\mathrm{HCl} 0 . \mathrm{IN}$ followed by a post incubation period of $\mathrm{Ih}$ (series $\mathrm{HCl} 0 . \mathrm{IN} \mathrm{lh}+\mathrm{Ih}$ post incubation). Magnification 20x. Scale bar $=100 \mu \mathrm{m}$.

After 12 days of differentiation (Figure 1C), the squamous layer appears more similar to the ex vivo morphology, suggesting that this model is a more predictive and robust candidate to be used as a test system.

In Figure $2 \mathrm{HO} 2 \mathrm{E}$ tissue morphology by H\&E staining before and after acid treatment is shown. Compared to the control (NC) the tissues exposed to $\mathrm{HCl} 0.1 \mathrm{~N}$ (pH 1.2) during the $1 \mathrm{~h}$ showed a modified morphology: enlarged intercellular spaces and diffuse spongiosis are responsible for thickness modification increase.

\section{TEER Measurements}

The TEER values expressed as \% with respect to negative control to which $100 \%$ TEER has been assigned are reported in Figure 3.
TEER values were not significantly different when measured immediately after $\mathrm{HCl}$ exposure or after 1 hour post incubation.

According to literature findings on oesophageal biopsies, ${ }^{27}$ TEER values on HO2E tissues exposed to acid damage were expected to drastically decrease but these results, apparently unexpected, have an explanation. TEER measurements reflect the global resistance of the barrier, linked both to the TJ structure and tissue thickness. The measured TEER values are coherent and reflect the increased tissue thickness observed after acid exposure (Figure 2). An increase of TEER values following exposure to acidic chemicals were previously reported in the literature, ${ }^{11,12}$ and were correlated with the consequences of cell swelling and increased thickness.

In our experience, in the absence of significant and irreversible proteins damage or denaturation (for example, as it

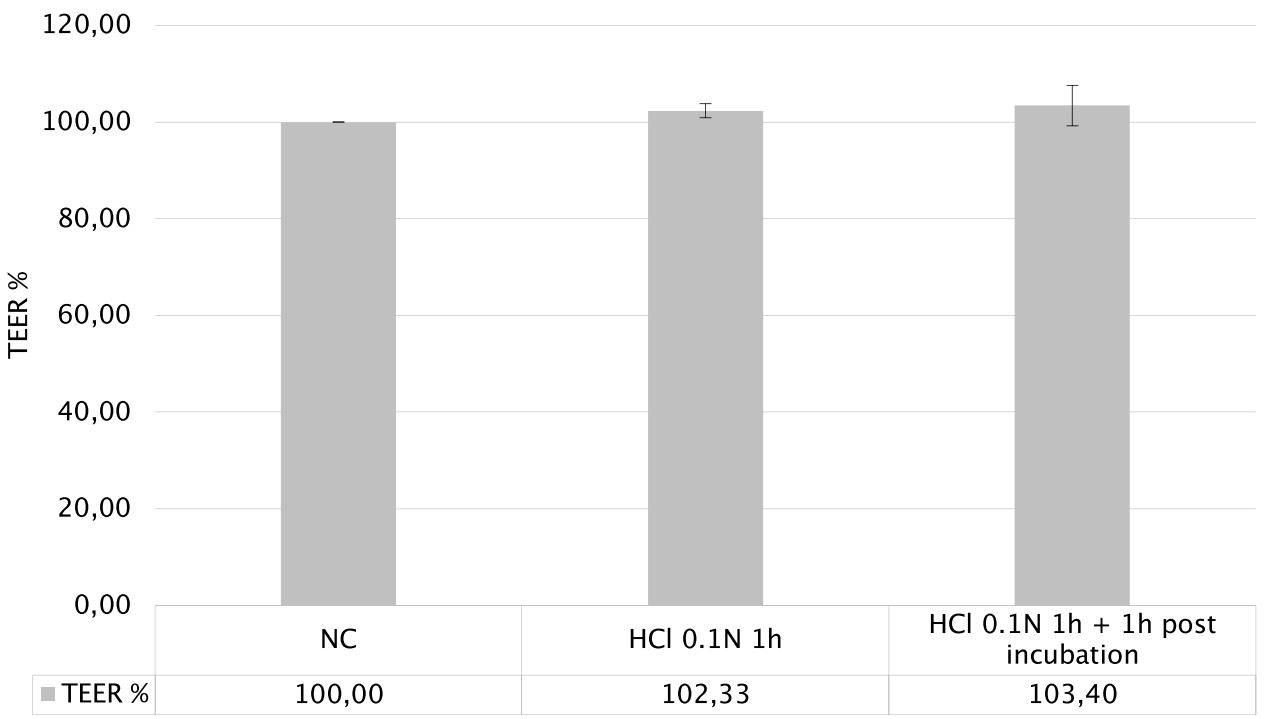

Figure 3 TEER\% values of $\mathrm{HO} 2 \mathrm{E}$ tissues treated with $\mathrm{HCl} 0 . \mathrm{IN}(\mathrm{pH} \mathrm{I} .2)$ during $\mathrm{Ih}$ (series $\mathrm{HCl} 0 . \mathrm{IN}$ ) and after Ih post incubation (series $\mathrm{HCl} 0 . \mathrm{IN}+\mathrm{Ih}$ post incubation) compared to HOE2 tissues treated with phosphate buffered saline (NC). 
occurs in the presence of surfactants or basic $\mathrm{pH}$ ), the measure of TEER immediately after epithelial acid damage is often variable and leads to unclear conclusions. This statement is also confirmed by the recommendation not to measure TEER in an acidic environment on an epithelial model as reported in OECD TG 494 (Vitrigel-Eye Irritancy test method), where test chemicals with a $\mathrm{pH} \leq 5$ are excluded from the applicability domain of the test method. For these reasons, TEER measurements in the early readout after damage (within $1 \mathrm{~h}$ ) have been considered not suitable and a not robust parameter to evaluate the oesophageal epithelium response to acid damage, since it suffered from an experimental bias.

\section{Immunofluorescence Analysis CLDN-I and CLDN-4}

In Figure 4 the immunofluorescent images of CLDN-1 and CLDN-4 double staining in $\mathrm{HO} 2 \mathrm{E} / 12$ tissues treated with saline solution (NC), exposed to $\mathrm{HCl} 0.1 \mathrm{~N}(\mathrm{pH} 1.2)$ for 1 hour followed or not by 1 hour post incubation period, are presented. The IF signal quantification is reported in Figures 5 and 6 for CLDN-1 and CLDN-4, respectively.

In the NC, CLDN-1 (red) and CLDN-4 (green) expression is homogenous within basal and apical compartments, particularly in the supra-basal and basal layers.

As illustrated in Figure 4 and quantified in Figure 5 immediately after acid damage, the CLDN-1 (red) signal was quantified as not different from the negative control. After 1 hour post incubation the IF signal significantly increased $(\mathrm{p}<0.01)$ compared to the $\mathrm{NC}$ and the $\mathrm{HCl} 0.1 \mathrm{~N}$ series; the protein localization was observed particularly in the most superficial layer and it appeared more dense around each single cell, a mislocalization that can be associated to a barrier impairment.

CLND-4 (green) protein was almost absent at both timepoints compared to the negative control (Figure 4) corresponding to severe damage of the TJ structure: as reported in
Figure 6, a significant reduction of IF signal has been quantified at both timepoints $(p<0.01)$ compared to the NC. By comparing the results between the 2 timepoints ( 1 hour compared to 1 hour + post-incubation) a not significant increase of protein level was observed, suggesting that the TJ structure was not fully recovered at this time but a physiological mechanism was stimulated as a first attempt to recover the barrier function. This early recovery mechanism was expected as reported in literature findings. $9,15,28$

The immunofluorescence results on CLDN-1 and CLND4, whose expression increased during the post incubation period compared to their expression just after acid removal, allows us to make the hypothesis that a physiological recovery from acid damage had already started at this time, involving both proteins.

\section{ZO-I}

In Figure 7 the immunofluorescent images of $\mathrm{ZO}-1$ in $\mathrm{HO} 2 \mathrm{E}$ tissues are presented and the corresponding IF signal quantification is reported in Figure 8.

As shown in Figure 7, ZO-1 protein in the negative control is poorly expressed in our experimental conditions, by using LED based microscopy. After exposure to $\mathrm{HCl}$ $0.1 \mathrm{~N}$, the protein appears localized mainly in the cytoplasm and its signal is significantly increased after 1 hour $(\mathrm{p}<0.05)$ and even more significantly after 1 hour of post incubation ( $p$ $<0.01$ ) (Figure 8).

The ZO-1 expression is upregulated immediately after the damage and exhibits higher expression values (however not statistically significant) during the post incubation period. We have made the hypothesis that this increased expression is a first attempt of the epithelium to recover barrier function within a very short experimental window (1h) after acidinduced damage.
NC

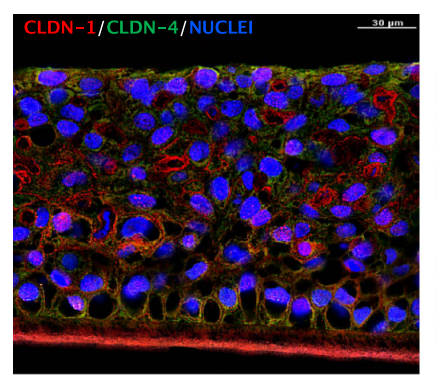

HCI 0.1N 1h

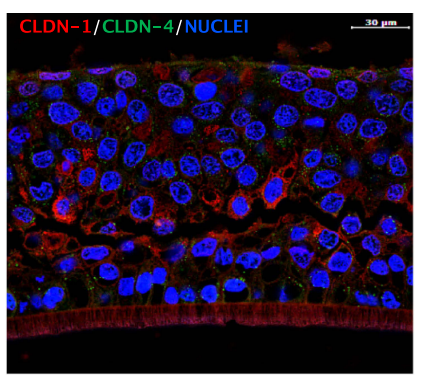

HCl 0.1N 1h + 1h post incubation

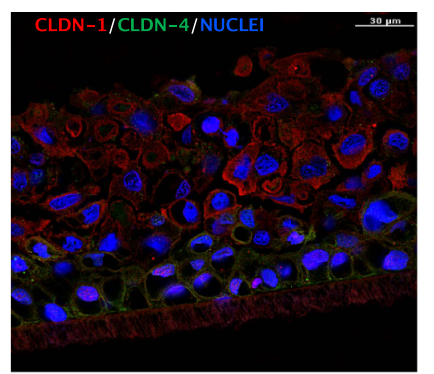

Figure 4 Immunofluorescence analysis of CLDN-I and CLDN-4 double staining in untreated HO2E/I2 tissues (NC) and HO2E/I2 exposed to HCI 0.IN (pH I.2) for Ih without (series $\mathrm{HCl} 0 . \mathrm{IN} \mathrm{Ih}$ ) or with Ih post incubation period (series $\mathrm{HCl} 0 . \mathrm{IN} \mathrm{Ih}+\mathrm{Ih}$ post incubation). Nuclei are stained in blue (DAPI). Magnification 63x. Scale bar = $30 \mu \mathrm{m}$. Representative images selected within triplicate series. 


\section{CLDN-1 quantification}

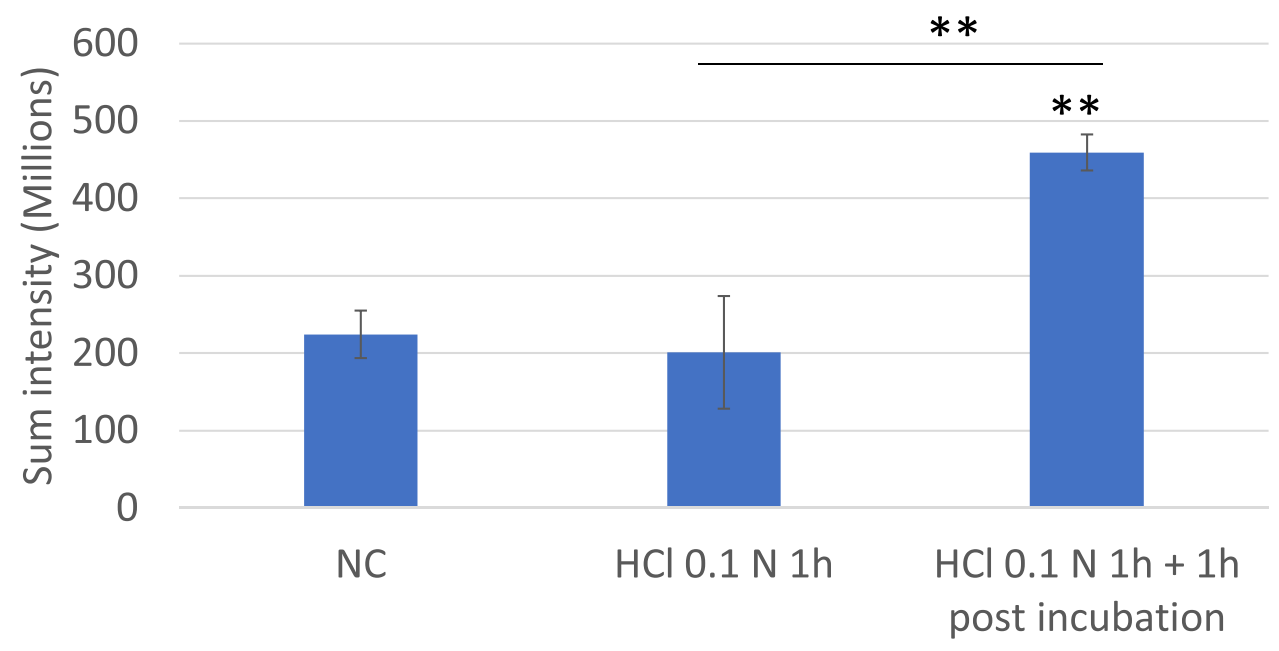

Figure $5 \mathrm{CLDN}$-I quantification performed on triplicate series of HO2E/I2 tissues treated with saline solution (NC) or exposed to $\mathrm{HCl} 0 . \mathrm{IN}$ (pH I.2) for Ih without (series $\mathrm{HCl} 0 . \mathrm{IN} \mathrm{Ih}$ ) or with Ih post incubation period (series $\mathrm{HCl} 0 . \mathrm{IN} \mathrm{Ih}+\mathrm{Ih}$ post incubation). The signal of CLDN-I was quantified using Tilescan technology which allows evaluation of the protein expression on the entire tissue section. Statistical significance compared to the NC and between the two series treated with $\mathrm{HCl}$ IN are reported: $* *_{p}<0.01$.

\section{CLDN-4 quantification}

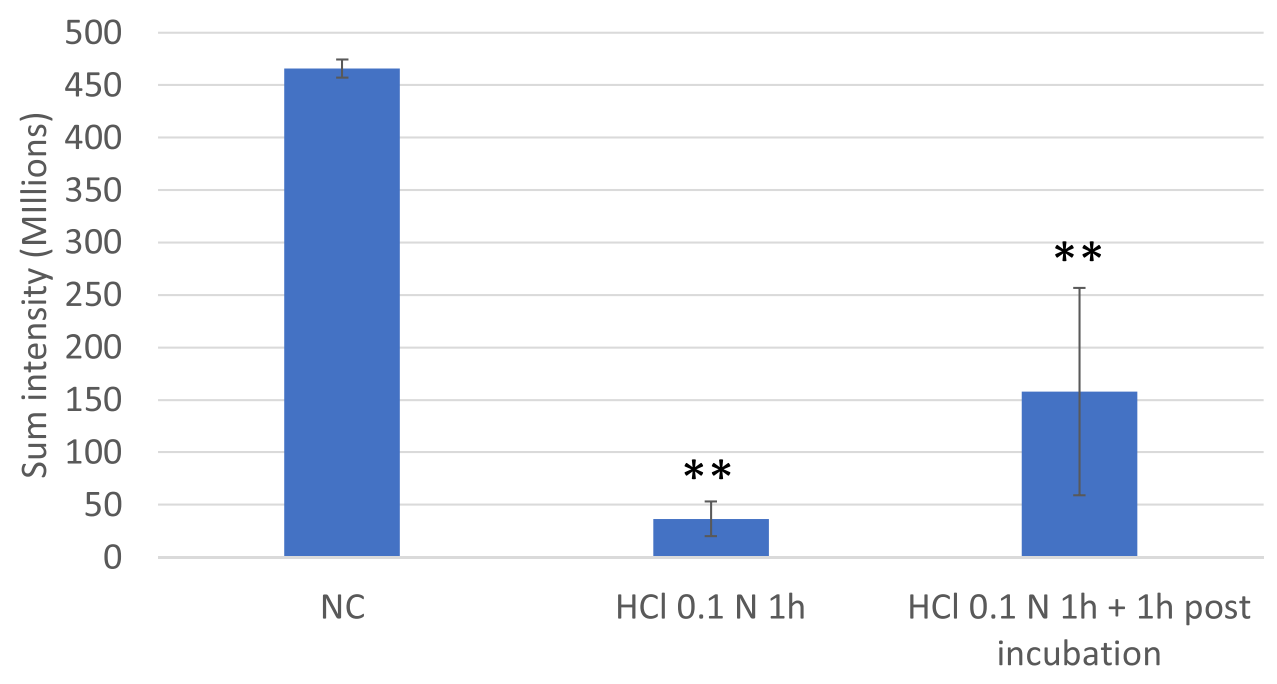

Figure $6 \mathrm{CLDN}-4$ quantification performed on triplicate series of HO2E/I2 tissues treated with saline solution (NC) or exposed to HCl $0.1 \mathrm{~N}$ (pH I.2) for Ih without (series $\mathrm{HCl} 0.1 \mathrm{~N} \mathrm{Ih}$ ) or with $\mathrm{Ih}$ post incubation period (series $\mathrm{HCl} 0 . \mathrm{IN} \mathrm{Ih}+\mathrm{lh}$ post incubation). The signal of CLDN-4 was quantified using Tilescan technology which allows evaluation of the protein expression on the entire tissue section. Statistical significance compared to NC: **p $<0.0$ I. Non statistical significance between the two series treated with $\mathrm{HCl} 0 . \mathrm{IN}: \mathrm{p}>0.05$.

Furthermore, since ZO-1 is poorly expressed in ex vivo oesophagus in physiological conditions and being a protein that links tight junction (TJ) transmembrane proteins such as claudins, it may be possible that the ZO1 expression could significantly increase as a consequence of the decrease of CLDN-4 expression.

\section{E-Cadherin}

In Figure 9 the immunofluorescent images of E-cadherin in $\mathrm{HO} 2 \mathrm{E} / 12$ tissues are presented and the corresponding IF signal quantification is reported in Figure 10. In Figure 9 E-cadherin localization within the tissue is visible. In the $\mathrm{NC}$ the protein is regularly localized on the cytoplasmic 


\section{NC}

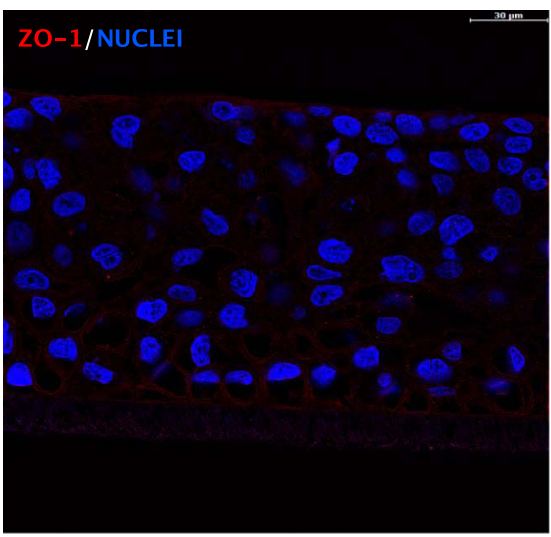

HCI 0.1N 1h

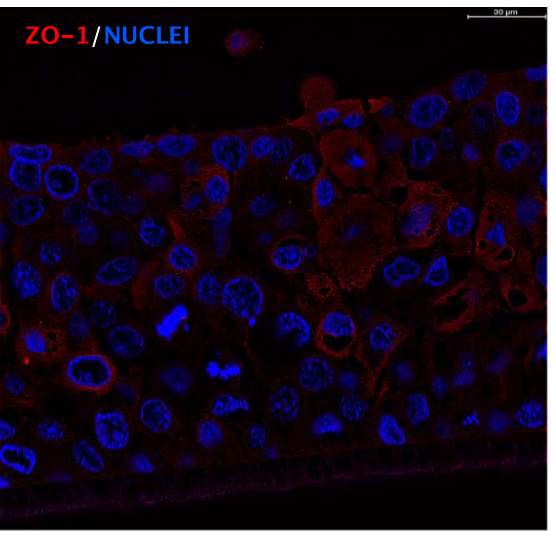

$\mathrm{HCl} 0.1 \mathrm{~N} 1 \mathrm{~h}+1 \mathrm{~h}$ post incubation

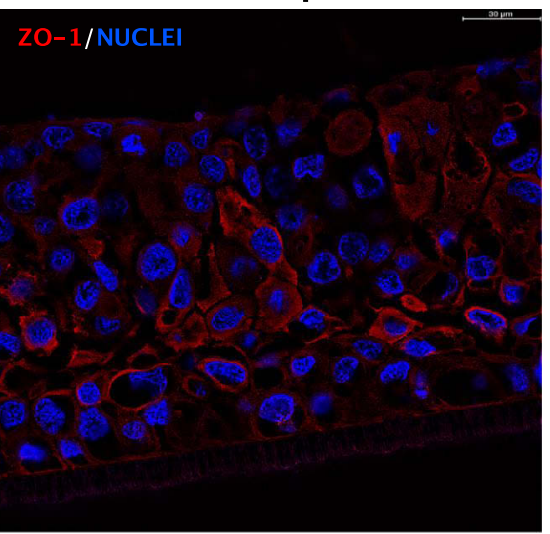

Figure 7 Immunofluorescent staining of ZO-I in untreated HO2E/I 2 tissues (NC) and HO2E/I2 exposed to $\mathrm{HCl} 0 . \mathrm{IN}$ (pH I.2) for Ih without (series $\mathrm{HCl} 0 . \mathrm{IN}$ Ih) or with Ih post incubation period (series $\mathrm{HCl} 0 . \mathrm{IN} \mathrm{Ih}+\mathrm{Ih}$ post incubation). Nuclei are stained in blue (DAPI). Magnification $63 \mathrm{x}$. Scale bar $=30 \mu \mathrm{m}$. Representative images selected within triplicate series.

\section{ZO-1 quantification}

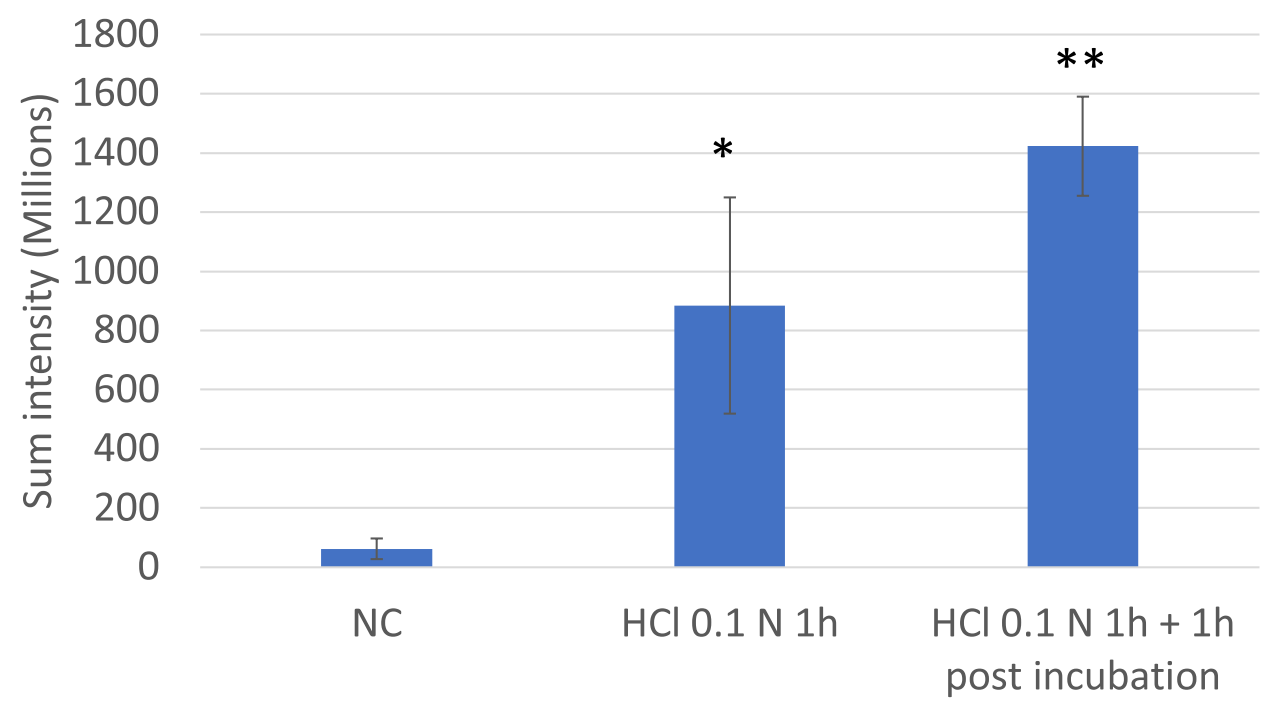

Figure $8 \mathrm{ZO}-\mathrm{I}$ quantification performed on triplicate series of $\mathrm{HO} 2 \mathrm{E} / \mathrm{I} 2$ tissues treated with saline solution ( $\mathrm{NC}$ ) or exposed to $\mathrm{HCl} 0 . \mathrm{IN}$ (pH I.2) for Ih without (series $\mathrm{HCl} 0 . \mathrm{IN} \mathrm{Ih}$ ) or with $\mathrm{Ih}$ post incubation period (series $\mathrm{HCl} 0 . \mathrm{IN} \mathrm{Ih}+\mathrm{Ih}$ post incubation). The signal of ZO-I was quantified using Tilescan technology which allows evaluation of the protein expression on the entire tissue section. Statistical significance compared to NC: ${ }^{*} p<0.05$, ${ }^{* *} p<0.01$. Non statistical significance between the two series treated with $\mathrm{HCl} 0.1 \mathrm{~N}: \mathrm{p}>0.05$.

membrane while after treatment with $\mathrm{HCl} 0.1 \mathrm{~N}$ for 1 hour and in the post incubation period the localization appears more cytoplasmic, suggesting that acid treatment causes mis-localization of E-cadherin, which could compromise the oesophageal barrier function.

However, the overall protein expression quantified as an IF signal does not support a significant change between the two experimental conditions (Figure 10, $\mathrm{p}>0.05)$.

In contrast with ZO-1 behaviour, the E-Cadherin signal appears stable just after damage induction (as confirmed by signal quantification in Figure 10) while decreasing during the post-incubation period. This behaviour has to be further investigated but could be linked to the protein cleavage process which is mediated by a cytoplasmic metalloprotease that certainly requires a longer time to be established. ${ }^{8}$

\section{MUCI}

In Figure 11 the immunofluorescent images of MUC1 in $\mathrm{HO} 2 \mathrm{E} / 12$ tissues are presented and the corresponding IF signal quantification is reported in Figure 12. 
NC

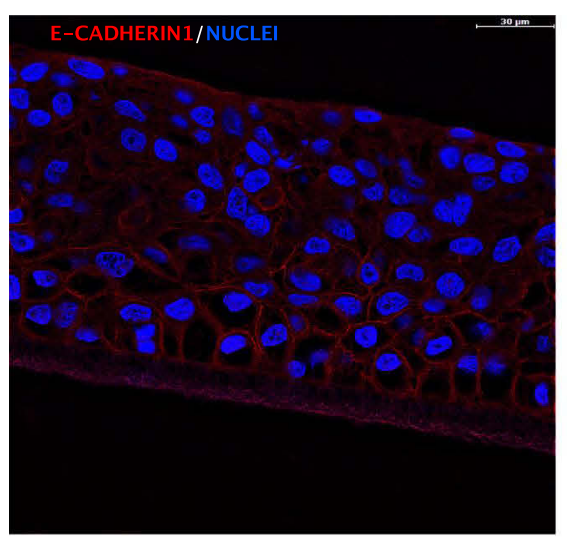

$\mathrm{HCl} 0.1 \mathrm{~N}$ 1h

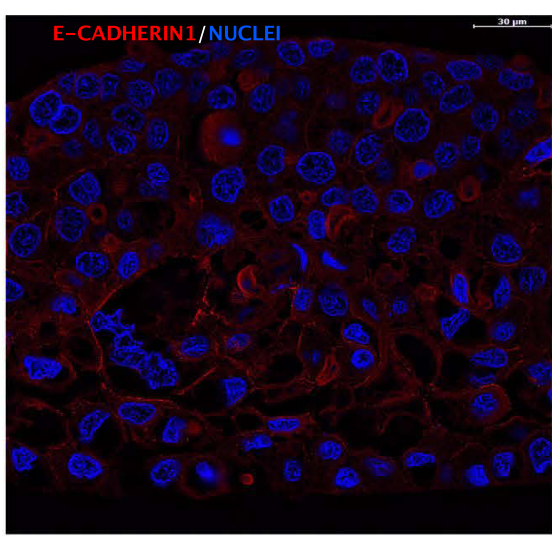

$\mathrm{HCl} 0.1 \mathrm{~N} 1 \mathrm{~h}+1 \mathrm{~h}$ post incubation

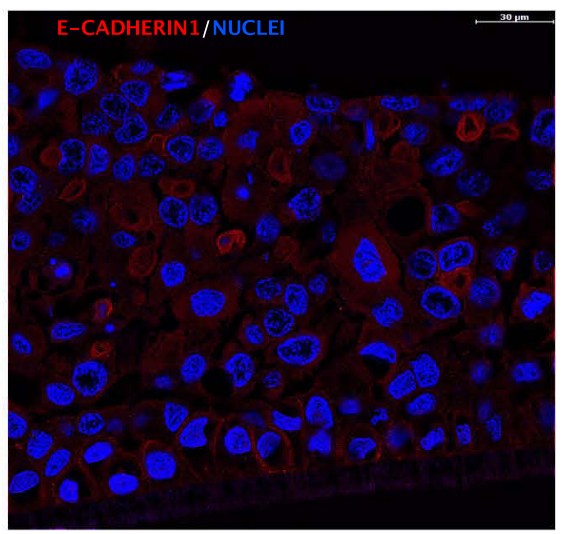

Figure 9 Immunofluorescence of E-Cadherin in untreated $\mathrm{HO} 2 \mathrm{E} / \mathrm{I} 2$ tissues $(\mathrm{NC})$ and $\mathrm{HO} 2 \mathrm{E} / \mathrm{I} 2$ exposed to $\mathrm{HCl} 0 . \mathrm{IN}(\mathrm{pH} \mathrm{I} .2$ ) for Ih without (series $\mathrm{HCl} 0 . \mathrm{IN}$ Ih) or with Ih post incubation period (series $\mathrm{HCl} 0 . \mathrm{IN} \mathrm{Ih}+\mathrm{Ih}$ post incubation). Nuclei are stained in blue (DAPI). Magnification $63 \mathrm{x}$. Scale bar $=30 \mu \mathrm{m}$. Representative images selected within triplicate series.

\section{E-CADHERIN quantification}

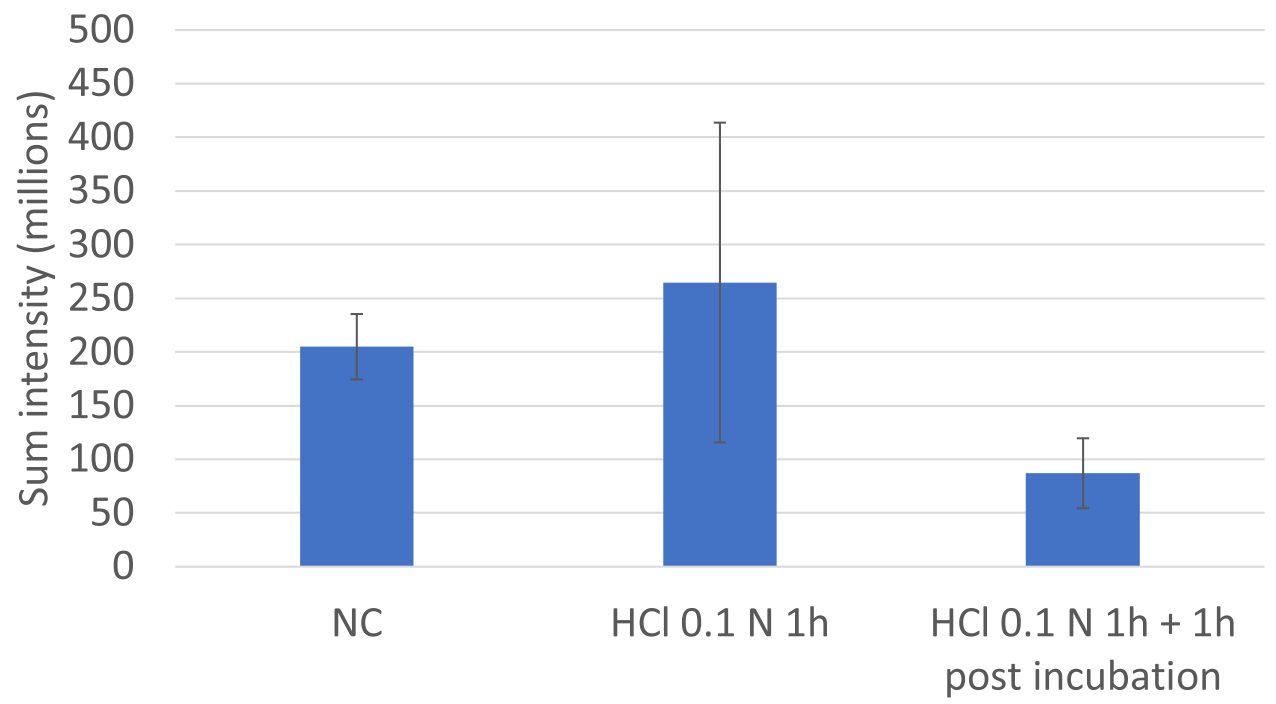

Figure $10 \mathrm{E}$-cadherin quantification performed on triplicate series of $\mathrm{HO} 2 \mathrm{E} / \mathrm{I} 2$ tissues treated with saline solution ( $\mathrm{NC}$ ) or exposed to $\mathrm{HCl} 0 . \mathrm{IN}$ ( $\mathrm{pH} \mathrm{I} .2$ ) for Ih without (series $\mathrm{HCl} 0 . \mathrm{IN} \mathrm{Ih}$ ) or with $\mathrm{Ih}$ post incubation period (series $\mathrm{HCl} 0 . \mathrm{IN} \mathrm{Ih}+\mathrm{Ih}$ post incubation). The signal of E-Cadherin was quantified using Tilescan technology which allows evaluation of the protein expression on the entire tissue section. Because of the high SD the differences observed are not statistically significant compared to NC.

In Figure 11 the protein is localized around the nuclei, at cytoplasmic and membrane levels for the $\mathrm{NC}$ as well as for the tissue series that have undergone acid treatment.

MUC1 plays an important role in protecting the oesophageal mucosa by membrane-bound mucins. In the established experimental conditions, MUC1 localization and expression remain stable immediately after acid exposure while they significantly increase $(\mathrm{p}<0.01)$ during the post incubation period (Figure 12). This behavior has been observed also for CLDN-1 and it seems to be associated with a defense mechanism developed to counteract the devastating effect of acid on the oesophageal mucosa as already reported in literature. ${ }^{4,26}$

\section{Conclusion}

GERD syndrome is characterized by oesophageal barrier impairment and changes in membrane-bound mucin expression, particularly MUC1. Literature reports that at TJs level other relevant biomarkers could have a functional role in restoring the damage that occurs at oesophageal level after acute or occasional exposure to noxious acid gastric fluids, in particular CLDN-1 and CLDN-4. 


\section{NC}

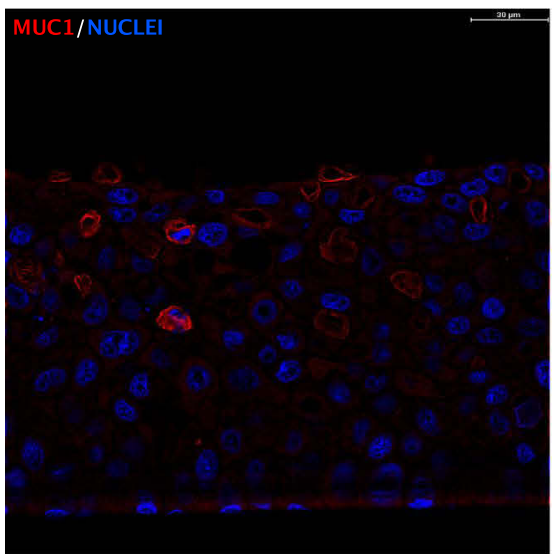

HCl 0.1N 1h

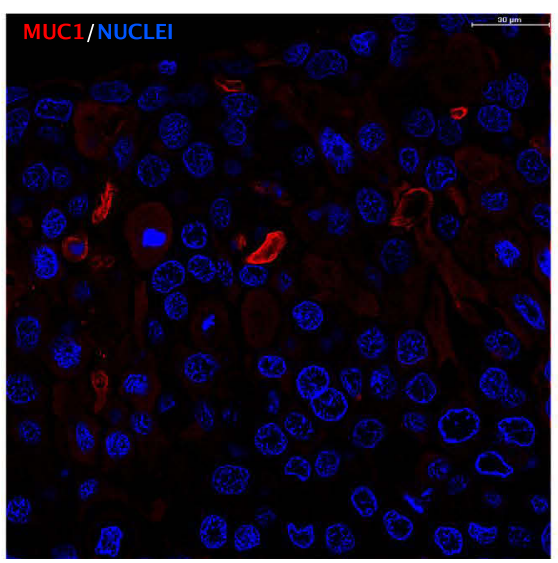

$\mathrm{HCl} 0.1 \mathrm{~N} 1 \mathrm{~h}+1 \mathrm{~h}$ post incubation

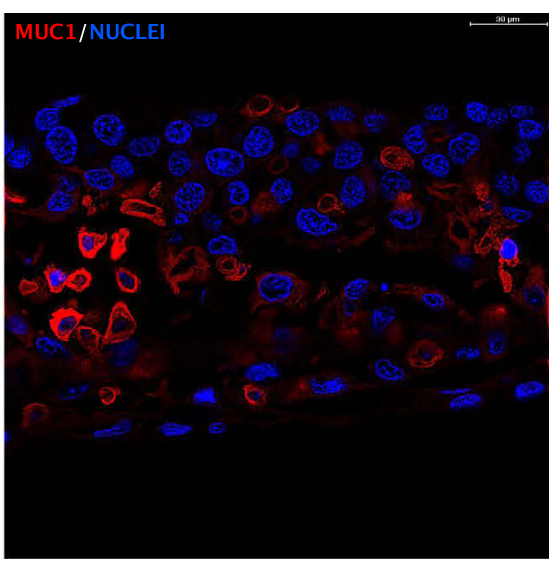

Figure II Immunofluorescence staining of $\mathrm{MUCl}$ in untreated $\mathrm{HO} 2 \mathrm{E} / \mathrm{I} 2$ tissues (NC) and $\mathrm{HO} 2 \mathrm{E} / \mathrm{I} 2$ exposed to $\mathrm{HCl} 0 . \mathrm{IN}$ (pH I.2) for Ih without (series $\mathrm{HCl} 0 . \mathrm{IN} \mathrm{Ih)} \mathrm{or}$ with $\mathrm{Ih}$ post incubation period (series $\mathrm{HCl} 0 . \mathrm{IN} \mathrm{Ih}+\mathrm{Ih}$ post incubation). Nuclei are stained in blue (DAPI). Magnification $63 \mathrm{x}$. Scale bar $=30 \mu \mathrm{m}$. Representative images selected within triplicate series.

\section{MUC-1 quantification}

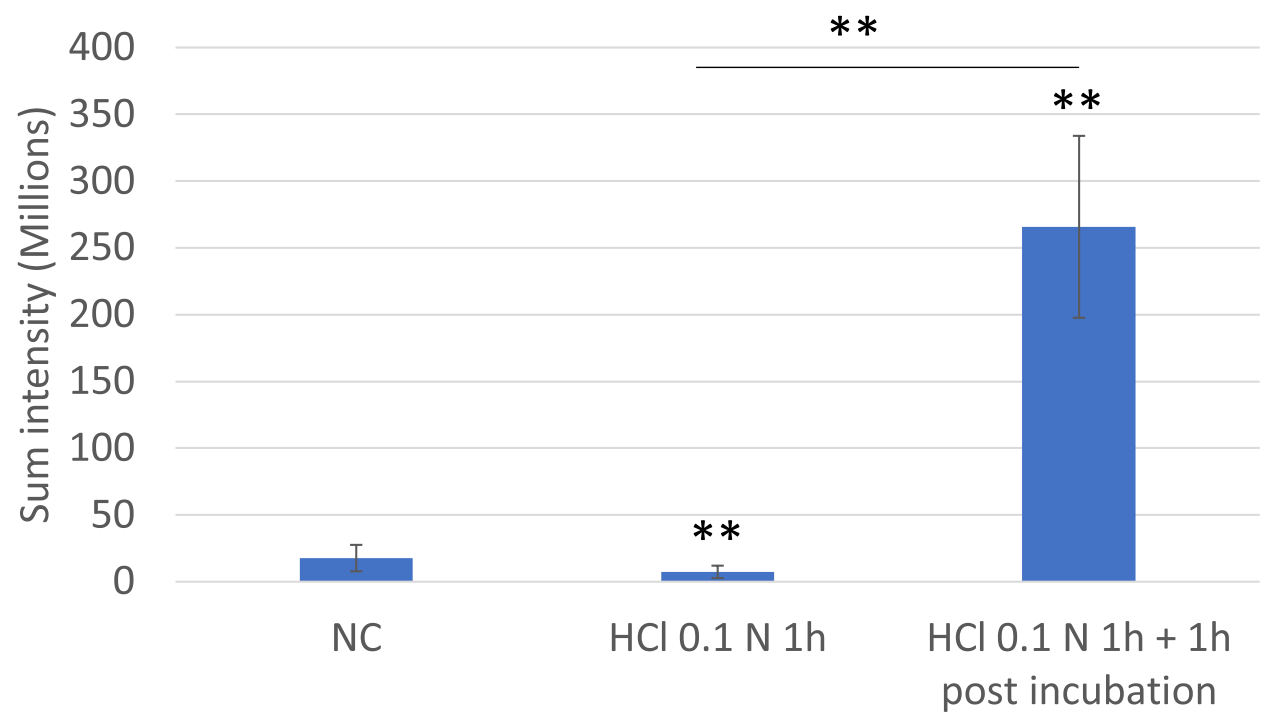

Figure $12 \mathrm{MUCl}$ quantification performed on triplicate series of $\mathrm{HO} 2 \mathrm{E} / \mathrm{I} 2$ tissues treated with saline solution ( $\mathrm{NC}$ ) or exposed to $\mathrm{HCl} 0 . \mathrm{IN}$ ( $\mathrm{pH} \mathrm{I} .2$ ) for Ih without (series $\mathrm{HCl} 0 . \mathrm{IN} \mathrm{Ih}$ ) or with $\mathrm{Ih}$ post incubation period (series $\mathrm{HCl} 0 . \mathrm{IN} \mathrm{Ih}+\mathrm{Ih}$ post incubation). The signal of $\mathrm{MUCl}$ was quantified using Tilescan technology which allows evaluation of the protein expression on the entire tissue section. Statistical significance compared to the NC and between the two series treated with $\mathrm{HCl}$ IN are reported: ${ }^{* *} p<0.01$.

A pre-clinical model based on a new 3D human reconstructed human oesophageal epithelium model has been developed to investigate structural and functional modifications at the oesophageal epithelium level following exposure to an acid solution as a surrogate of noxious refluxate thus mirroring the microenvironment and mechanisms that are the basis of GERD. HO2E/12 tissues were treated with $\mathrm{HCl} 0.1 \mathrm{~N}$ $(\mathrm{pH}=1.2)$ for 1 hour with readout immediately after $\mathrm{HCl}$ $0.1 \mathrm{~N}$ removal or after 1 hour post incubation period.
Being the first time in our knowledge that this $3 \mathrm{D}$ in vitro model has been applied as a test system to develop a preclinical experimental design, we have decided to adopt a histomorphology and immunohistochemistry approach and to investigate the structural tissue changes through immunolocalization of the epithelial barrier function biomarkers: CLDN-1, CLDN-4, ZO-1, E-Cadherin and MUC1.

As a general consideration, the expression of the different proteins investigated in a defined and relatively short 
experimental windows after $\mathrm{HCl}$ exposure suggests that not all these proteins can be used as relevant biomarker to follow the restoring of TJs structure and epithelial barrier itself after damage. In our experimental conditions it has been possible to determine a significant modification of CLDN-1 and MUC1 expression and localization after exposure to an acid microenvironment $(\mathrm{pH} 1.2)$ and this modification was particularly relevant 1 hour after the acid exposure and during 1 hour post incubation period.

However, this severe damage to TJs and oesophageal epithelial structure was not disruptive, and it has been shown that the $3 \mathrm{D}$ viable tissue model has the potential to recover the damage within a very short experimental window (1h). This recovery involves a different localization of MUC1, ZO-1 and CLDN-4 and their significantly increased expression compared to negative control.

Apart from TEER that has been shown to be not applicable to our experimental conditions compared to other GERD models, we have found a good correlation of these experimental data with literature findings on different experimental models as reported in Table 1.

The in vitro developed GERD model on 3D human reconstructed and fully viable tissue has allowed the recreation, in vitro, of the main feature of the impaired epithelial barrier typically found in the biopsies of GERD patients: the disease condition was shown to be reversible, and it was maintained during $1 \mathrm{~h}$ post incubation. The established model can be useful to investigate the mechanism of action of formulations acting on this specific pathophysiological condition and/or developed to potentiate the physiological defence mechanisms of oesophageal mucosa (eg TJ proteins and mucus production). By using adapted protocols, preclinical efficacy studies can be performed to evaluate the protective mechanisms on oesophageal epithelium from acute tissue damage by performing a pretreatment or to investigate the properties to restore epithelium integrity after damage (post-treatment).

Further investigations are in progress in order to explore the relevance of additional biochemical and molecular parameters, to extend the experimental window and to validate the approach with reference formulations. In parallel, the use of gastric fluids including pepsin has been done with encouraging results in terms of test system resistance to a more drastic challenge. Reconstructed human oesophageal epithelium based experimental systems, if correctly developed within a suitable experimental framework, can represent a robust and reliable preclinical platform for other disease models (eosinophilic esophagitis, Barrett's oesophagus) to substantiate specific product mechanisms of action during the development of new formulations. Last but not least, the proposed approach has high ethical relevance with respect to the use of animals and it is sustainable with respect to Directive EU n. 2010/63 which also promotes, for preclinical studies, the replacement of animal testing by scientifically validated preclinical models.

\section{Acknowledgments}

This research work did not require any review/approval by institutional review board or ethics committee since it is based on in vitro methodologies on commercially available human derived reconstructed tissues.

\section{Disclosure}

The authors have no conflicts of interest to declare.

\section{References}

1. Kandulski A, Malfertheiner P. Gastroesophageal reflux disease - from reflux episodes to mucosal inflammation. Nat Rev Gastroenterol Hepatol. 2012;9(1):15-22. doi:10.1038/nrgastro.2011.210

2. Dent J, El-Serag HB, Wallander MA, Johansson S. Epidemiology of gastroesophageal reflux disease: a systematic review. Gut. 2005;54 (5):710-717. doi:10.1136/gut.2004.051821

3. Marcinkiewicz M, Namiot Z, Edmunds MC, et al. Detrimental impact of acid and pepsin on the rate of luminal release of transforming growth factor $\alpha$ : its potential pathogenetic role in the development of reflux esophagitis. J Clin Gastroenterol. 1996;23 (4):261-268. doi:10.1097/00004836-199612000-00005

4. Niv Y, Fass R. The role of mucin in GERD and its complications. Nat Rev Gastroenterol Hepatol. 2012;9(1):55-59. doi:10.1038/ nrgastro.2011.211

5. Burjonrappa SC, Reddimasu S, Nawaz Z, et al. Mucin expression profile in Barrett's, dysplasia, adenocarcinoma sequence in the esophagus. Indian $J$ Cancer. 2007;44(1):1-5. doi:10.4103/0019509X.31160

6. Guillem P, Billeret V, Buisine MP, et al. Mucin gene expression and cell differentiation in human normal, premalignant and malignant esophagus. Int $J$ Cancer. 2000;88(6):856-861. doi:10.1002/10970215(20001215)88:6<856::AID-IJC3>3.0.CO;2-D

7. Farquhar MG, Palade GE. Junctional complexes in various epithelia. J Cell Biol. 1963;17(2):375-412. doi:10.1083/jcb.17.2.375

8. Jovov B, Que J, Tobey NA, et al. Role of e-cadherin in the pathogenesis of gastroesophageal reflux disease. Am $J$ Gastroenterol. 2011;106(6):1039-1047. doi:10.1038/ajg.2011.102

9. Björkman EVC, Edebo A, Oltean M, et al. Esophageal barrier function and tight junction expression in healthy subjects and patients with gastroesophageal reflux disease: functionality of esophageal mucosa exposed to bile salt and trypsin in vitro. Scand J Gastroenterol. 2013;48(10):1118-1126. doi:10.3109/ 00365521.2013 .828772

10. Namiot Z, Sarosiek J, Marcinkiewicz M, et al. Declined human esophageal mucin secretion in patients with severe reflux esophagitis. Dig Dis Sci. 1994;39(12):2523-2529. doi:10.1007/BF02087685

11. Farré R, Van Malenstein H, De Vos R, et al. Short exposure of oesophageal mucosa to bile acids, both in acidic and weakly acidic conditions, can impair mucosal integrity and provoke dilated intercellular spaces. Gut. 2008;57(10):1366-1374. doi:10.1136/ gut.2007.141804 
12. Oshima T, Koseki J, Chen X, et al. Acid modulates the squamous epithelial barrier function by modulating the localization of claudins in the superficial layers. Labor Investig. 2012;92(1):22-31. doi:10.1038/labinvest.2011.139

13. Chen X, Oshima T, Shan J, et al. Bile salts disrupt human esophageal squamous epithelial barrier function by modulating tight junction proteins. Am J Physiol. 2012;303(2):G199-G208. doi:10.1152/ ajpgi.00454.2011

14. Fang Y, Chen $\mathrm{H}, \mathrm{Hu} \mathrm{Y}$, et al. Gastroesophageal reflux activates the NF- $\kappa \mathrm{B}$ pathway and impairs esophageal barrier function in mice. $\mathrm{Am}$ J Physiol. 2013;305(1):G58-G65. doi:10.1152/ajpgi.00438.2012

15. Mönkemüller K, Wex T, Kuester D, et al. Role of tight junction proteins in gastroesophageal reflux disease. BMC Gastroenterol. 2012;12(1):128. doi:10.1186/1471-230X-12-128

16. Orlando RC. The integrity of the esophageal mucosa. Balance between offensive and defensive mechanisms. Best Pract Res Clin Gastroenterol. 2010;24(6):873-882. doi:10.1016/j.bpg.2010.08.008

17. Bove M, Vieth M, Casselbrant A, et al. Acid challenge to the esophageal mucosa: effects on local nitric oxide formation and its relation to epithelial functions. Dig Dis Sci. 2005;50(4):640-648. doi:10.1007/s10620-005-2550-8

18. Tobey NA, Carson JL, Alkiek RA, Orlando RC. Dilated intercellular spaces: a morphological feature of acid reflux-damaged human esophageal epithelium. Gastroenterology. 1996;111(5):1200-1205. doi:10.1053/gast.1996.v111.pm8898633

19. Asaoka D, Miwa H, Hirai S, et al. Altered localization and expression of tight-junction proteins in a rat model with chronic acid reflux esophagitis. J Gastroenterol. 2005;40(8):781-790. doi:10.1007/ s00535-005-1628-6

20. Di Simone MP, Baldi F, Vasina V, et al. Barrier effect of Esoxx ${ }^{\circledR}$ on esophageal mucosal damage: experimental study on ex-vivo swine model. Clin Exp Gastroenterol. 2012;5(1):103-107. doi:10.2147/ CEG.S31404
21. Agostinis C, Bossi F, Mangogna A, et al. Protective and regenerative effects of a novel medical device against esophageal mucosal damage using in vitro and ex vivo models. Biomed Pharmacother. 2020;131:110752. doi:10.1016/j.biopha.2020.110752

22. Souza RF, Huo X, Mittal V, et al. Gastroesophageal reflux might cause esophagitis through a cytokine-mediated mechanism rather than caustic acid injury. Gastroenterology. 2009;137(5):1776-1784. doi:10.1053/j.gastro.2009.07.055

23. Takeuchi K, Nagahama K. Animal model of acid-reflux esophagitis: pathogenic roles of acid/pepsin, prostaglandins, and amino acids. Biomed Res Int. 2014;2014:1-10. doi:10.1155/2014/532594

24. Palmieri B, Merighi A, Corbascio D, et al. Fixed combination of hyaluronic acid and chondroitin-sulphate oral formulation in a randomized double blind, placebo controlled study for the treatment of symptoms in patients with non-erosive gastroesophageal reflux. Eur Rev Med Pharmacol Sci. 2013;17:3272-3278.

25. Oshima T, Miwa H. Gastrointestinal mucosal barrier function and diseases. J Gastroenterol. 2016;51:768-778. doi:10.1007/s00535016-1207-z

26. Namiot Z, Sarosiek J, Rourk RM, et al. Human esophageal secretion: mucosal response to luminal acid and pepsin. Gastroenterology. 1994;106(4):973-981. doi:10.1016/0016-5085(94)90756-0

27. Woodland P, Lee C, Duraysami Y, et al. Assessment and protection of esophageal mucosal integrity in patients with heartburn without esophagitis. Am J Gastroenterol. 2013;108:535-543. doi:10.1038/ ajg.2012.469

28. Capaldo CT, Farkas AE, Hilgarth RS, et al. Proinflammatory cytokine-induced tight junction remodeling through dynamic self-assembly of claudins. Mol Biol Cell. 2014;25(18):2710-2719. doi:10.1091/mbc.e14-02-0773
Clinical and Experimental Gastroenterology

\section{Publish your work in this journal}

Clinical and Experimental Gastroenterology is an international, peerreviewed, open access, online journal publishing original research, reports, editorials, reviews and commentaries on all aspects of gastroenterology in the clinic and laboratory. This journal is indexed on American Chemical Society's Chemical Abstracts Service (CAS)

\section{Dovepress}

The manuscript management system is completely online and includes a very quick and fair peer-review system, which is all easy to use. Visit http://www.dovepress.com/testimonials.php to read real quotes from published authors. 